\title{
OCCUPATIONAL THERAPY IN MENTAL HEALTH: A REVIEW OF THE LITERATURE
}

\section{CHRISTINE CRAIK}

Director of Undergraduate Occupational Therapy Studies, Brunel University, London

\section{Key Words}

Mental health

Literature review

Psychiatry

\section{Word count 5367}

Christine Craik MPhil, DMS, Dip COT, MIMgt, SROT

Director of Undergraduate Occupational Therapy Studies, Brunel University, Osterley Campus, Borough Road, Isleworth, Middlesex,TW7 5DU. Chairman of Mental Health Project Working Group of the College of Occupational Therapists 


\section{ABSTRACT}

This review of the literature was conducted as part of the development of a position paper on the way ahead for research, education and practice in occupational therapy in mental health. It included publications over the past decade and concentrated on the British Journal of Occupational Therapy. Recognising experience from other countries would be beneficial, aspects of the literature from the National Journals in American, Canada and Australia which were most relevant to practice in the UK were included. The shortage of articles on mental health was conspicuous and their diverse topics and descriptive nature were notable. In the UK literature, the clinical subjects featured most often were dementia, work rehabilitation, community mental health and forensic psychiatry, with other subjects either appearing infrequently or not being included. The literature from the other countries also explored new roles for occupational therapy, reflecting the changes in the delivery of mental health services. In the American Journal of Occupational Therapy there was concern about the declining number of occupational therapists working in mental health. The review identified major themes in the literature and posed questions for education, research and practice in occupational therapy and formed the foundation for the position paper.

INTRODUCTION 
This literature review formed part of the project established by the College of Occupational Therapists, to develop a position paper on the way ahead for research, education and practice in occupational therapy in mental health. An examination of the literature was a necessary starting point for the project. In order to limit the scope of the review some parameters were set. It was decided to include publications over the past ten years and to concentrate on the British Journal of Occupational Therapy. However, it was recognised the experience from other countries would be beneficial and so those aspects of the literature from the National Journals in American, Canada and Australia which were most relevant to practice in the UK were included. Although Occupational Therapy in Mental Health, a quarterly journal published in USA, includes relevant articles it was decided that to extend the review to include it would expand its specification too far.

In grouping the articles to discuss them, different choices could have been made; a specialist area of practice to one therapist will be routine to another. Consideration was given to classifying the articles under the headings of research, education and practice which were the topics of the project, but this did not prove feasible. Rather themes were identified which seemed to make sense of the material and created larger rather than smaller areas. Terminology changes over time and differs according to location. This review has used the language of the original publications and attempted to reflect current and non discriminatory terminology.

By publishing this literature review and other components of the project, it is hoped to provide not only valuable information for individual practitioners, managers, 
educators and researchers but also to add to the published body of knowledge about occupational therapy in mental health.

\section{BRITISH JOURNAL OF OCCUPATIONAL THERAPY}

\section{Scarcity}

In reviewing the literature in the British Journal of Occupational Therapy over the decade, there were a number of striking features. First was the scarcity of articles on mental health, for example in 1996, excluding reports and opinion pieces, 80 refereed articles were published and only $6(7.5 \%)$ related to mental health. This finding is reinforced by Mountain (1997) who, in a review of the literature from 1989 to 1996 using different categories, identified even fewer articles on mental health and remarked on the paucity of articles in psychiatry.

\section{Diversity}

Next, the diversity of topics within the broad subject of mental health was notable. Examples through the decade included educating sixth-formers about occupational therapy (Lake and Burgess, 1989); a pilot study on the use of assertiveness training in Canada (Brown and Carmichael, 1992); establishing occupational therapy in mental health in Jordan (Busuttil, 1994) and the benefits of fieldwork placements in community mental health settings in Australia (Lyons, 1995) These topics illustrated a further point as they appeared once and tended not to be succeeded by further articles. Thus, there were few recurring subjects over the period. This is a major deficiency for the profession as it does not demonstrate the development of practice 
based on previous publications. There were four clinical areas where several articles were published; occupational therapy with elderly mentally ill people, especially those with dementia, work rehabilitation, community mental health and forensic psychiatry. Although even here, work based on previous studies was the exception.

\section{Dementia}

Evans (1990) examined the workload of three community occupational therapists working with people with dementia and found that their role went beyond direct clinical contact. She suggested that caregivers could be considered as clients and that the provision of support to carers was a legitimate role for occupational therapists, contributing greatly to enabling people with dementia to remain in the community. Building on her previous work, Evans (1996) again recorded the community occupational therapists' workload in the same location and noted the small proportion of time spent in face-to-face contact with clients with dementia, in contrast to $60 \%$ of time allocated to non patient related activity. Also recognising the needs of carers of people with dementia Robinson (1992) portrayed the role of occupational therapy in a memory clinic. Although conducting functional assessments of clients in their own homes was a major feature, the organisation of an information course for carers met their greatest need. Designed to run over 7 weeks, one afternoon per week for 12 carers, the group was modified in response to feedback. Sainty (1993) in a qualitative study, interviewed eight people whose spouse had dementia. She explored the meaning of the marriage relationship and how the dementia of one partner had altered this. Also investigated was the concept of relief or respite and its meaning to carers. These are all small scale studies which, although of interest, are limited in their application. 
Bryant (1991) considered sensory integration therapy with confused elderly people in care. She outlined a sensory gardening group and a music group. Her account was clear and included aims, methods, timing, staffing and evaluation and her case studies demonstrated the value of the groups with these clients. Green (1995) explored reactions to an activity programme with similar clients in residential homes. Adopting a multifocused methodology, she observed residents, recorded their comments and interviewed relatives and staff. Overall relatives, staff and some residents valued the activity programme and the time allocated to it was increased. Although the study was conducted over a three week period and involved small numbers of respondents, it gave valuable information about these clients and could serve as a guide to the evaluation of programmes in other settings.

Two recent studies explored the use of Snoezelen with people with dementia. Pinkey (1997) compared the Snoezelen environment with a music relaxation group on the mood and behaviour of three people with dementia attending a day hospital. She found that Snoezelen produced positive results on mood but had limitations with those with less severe cognitive deficits and suggested its use as part of a combination of approaches. Baker et al (1997) conducted a larger, randomised, controlled trial to compare the short and long term effects of eight Snoezelen sessions and eight activity sessions on the behaviour, mood and cognition of 31 people with dementia attending two day hospitals. Patients were randomly assigned to the Snoezelen or activity groups and five different assessments were used pre-trial, mid-trial, post-trial and at follow up. The results indicated short term benefits in both groups in 
behaviour and mood and long term benefits in the Snoezelen group on socially disturbed behaviour.

\section{Work rehabilitation}

A review of the literature on work in psychiatric rehabilitation (Vostanis, 1990) included occupational therapy but also other aspects in a comprehensive account of early publications in this area. Oxley (1992) described the development of a prevocational assessment package for people with mental health problems. Garner (1995) discussed the establishment of a prevocational training programme in a regional secure unit which may also have relevance with different populations. In an opinion piece, Bertram and Linnett (1995) noted that the closure of a large Victorian mental hospital would end work rehabilitation for many patients and described an alternative, innovative work scheme. Also presenting alternative models, Creegan (1995) described the psychiatric vocational programmes she studied in North America. Oxley (1995) in a later article proposed a wide definition of work and presented a continuum of work rehabilitation opportunities. This theme was also included in a comprehensive literature review on work related activity for people with long term schizophrenia (Durham, 1997) She also noted methods of measuring the effectiveness of such programmes.

\section{Community mental health}

The move from hospital to community based services has been reflected in several articles, with the introduction of relaxation groups in primary health care (Westland, 1988) and a short description of a Living Skills Centre as part of community mental health services in Australia (Moss, 1990). McDougall (1992) examined the effect of 
an education programme about nutrition on the eating and shopping behaviour of 11 people with chronic schizophrenia living in the community and attending a day hospital. Although she concluded that there had been little effect, the article provides a valuable account of treatment approaches for this group of clients. In a larger study, Brewer et al (1994) surveyed the 169 users of 16 community groups in a network in south London where some success was indicated in engaging long-term clients. The need for further research to establish the longer term effectiveness of this engagement was recorded, identifying the opportunity for further research.

In another study of this client group, Bryant (1995) explored the use of social contact groups. She discovered that the users considered that they met their needs for social contact by providing regular opportunity to meet other users and engage in various social activities. Orford (1995), cognisant of role blurring in the community setting, developed and piloted a client centred, occupational performance initial interview for occupational therapists.

\section{Forensic psychiatry}

Flood, (1993) published a short personal view of the Reed report, on services for mentally disordered offenders, and its implications for occupational therapy. She highlighted the need for improved staffing levels and training at pre-registration and post-registration levels and the development of the role of occupational therapy. Lloyd (1995) reviewed the literature, identifying trends in this field which serves as a useful introduction to the subject. Garner (1995) followed her report of a prevocational training programme in a regional secure unit and with colleagues (Garner et al, 1996) investigated the possible correlation between patterns of structured activity and 
incidents of self harm in the unit. Although the authors found the relationship inconclusive, they reported that rehabilitation staff considered that 'occupational therapy is effective in addressing needs in such area as self-esteem, self-confidence, problem solving, social skills and anxiety management' (p160). Highlighting the distinctions between forensic clients and those in psychiatric intensive care units, Best (1995) outlined the establishment of occupational therapy in this developing area, made comparisons with mainstream mental health and identified the challenges for the profession.

\section{Specialised Areas}

Other themes in the literature were developing or specialised areas of practice for example methods of coping with tranquilliser misuse (Blank,1990); treatment approaches for people with eating disorder in Australia (Lim and Agnew, 1994); occupational therapy following major disaster (Roberts, 1995); theoretic principles used by occupational therapists in play therapy (Telford and Ainscough, 1995) and anger management (O’Neill, 1995a,b) These articles are valuable in alerting practitioners to developments in the profession and they supply a useful introduction to them, but they could indicate that occupational therapists prefer to diversify and extend the boundaries of practice rather than to justify and substantiate current practice.

\section{Not Featured}

Of interest were the subjects which did not feature frequently. Apart from the articles already noted, there has been little published on occupational therapy for people with enduring mental health problems. For example, there were only two articles on 
depression. Bracegridle (1991) in a brief account examined the stereotyping of woman as a factor in their increased risk of developing depression but did not identify the implications for occupational therapy. Gilbert and Strong (1994) reported on cognitive behavioural therapy carried out by an occupational therapist and two nurses at a private psychiatric hospital in Australia. Given the prevalence of depression and the distress it causes, it is regrettable that there were no studies published which evaluated occupational therapy intervention with this client group.

\section{Evaluation}

Throughout the decade the emphasis has been on descriptive articles, with few examples of evaluation of practice or the results of research. This echoes the conclusions of the wider review of literature in BJOT conducted by Mountain (1997). Useful guides to evaluation are the multifocused methodology with the residents in a care home (Green,1995); the randomised controlled trial comparing the effects of Snoezelen and activity sessions with people with dementia (Baker et al, 1997) and methods of measuring the effectiveness of work related activity for people with long term schizophrenia (Durham, 1997). A valuable review of choosing measures to demonstrate effectiveness in mental health was presented by Jeffrey (1993). She offered a critique of various measures, supported by a extensive list of references which provided further detail. Lloyd and Maas (1997) summarised recent research findings in a comprehensive review of the literature on the use of groups in occupational therapy.

\section{Occupation}


Apart from the articles on work, few others featured activity or occupation, the exceptions being related mainly to activities of daily living. Carpenter et al (1990), in examining the occupational therapy requirements of inpatients at a district psychiatric unit, identified the need for activity of 134 inpatients. Activities of daily living were most frequently recognised with activities related to work second and social interaction activity groups third. This latter group included creative and craft groups. Living and social skills as part of the community mental health services in Australia were described by Moss (1990) and shopping and eating by McDougall (1992). No articles were found which evaluated activity as a treatment medium. Given that the profession espouses occupation as one of its distinguishing features, this is surprising and may explain why occupational therapists and others have difficulty in defining the profession.

\section{Role and attitudes}

Defining the role of occupational therapy and the attitudes of others to it has been featured. Joice and Coia (1989) examined the role of the profession in the multidisciplinary team and highlighted its value. They identified a lack of understanding of the range of skills which could be provided and that therapists needed to be more confident of their contribution. They suggested that this lack of confidence was linked to the scarcity of evaluative research in the profession. An early consumer opinion study by Sexton (1992), gathered views about occupational therapy from the users of a mental health day facility. Using a Likert scale based on the original aims of the facility, she found that the users judged the facility to be most successful in providing support and increasing social contact. The aim of being activity based was rated the joint third most successful, with an increase in the number 
of activities indicated. This is an interesting study which could form the foundation for others to replicate or enhance.

Harries and Caan (1994) examined views about occupational therapy of 28 inpatients and 19 ward staff in a psychiatric hospital. Employing a Likert scale of 20 statements describing possible purposes of occupational therapy, the majority of patients and staff agreed with the 10 statements which the occupational therapists had identified as the main purposes of the profession. Again this scale and study could provide the basis for further study.

Kaur et al (1996) also studied the attitudes of mental health professionals about occupational therapy and found that there was a blurring of roles with other professions. Many staff were able to recognise the main functions of occupational therapy but lacked confidence in this and did not fully utilise their knowledge in practice. Gilbert and Strong (1997) examined the attitudes and knowledge of 62 Australian occupational therapy students about psychiatry. Using a standardised instrument, they found that students had a positive attitude towards psychiatry but noted the low profile of the profession in this area. This instrument, although somewhat dated, could be a useful tool for others to employ in further studies.

\section{Scope}

This emphasis on low profile and lack of confidence may be linked, not only to the dearth of published research (Joice and Coia, 1989) but also to the limited literature describing the scope of the profession in mental health. Two exceptions were, first, Crawford and her colleagues (1992) who surveyed 339 mental health occupational 
therapists to identify the profile of the profession in Trent Region and obtain data for workforce planning, and, secondly Evans (1996) who recorded the workload of community occupational therapists working with people with dementia in Dorset. The Trent study reported data from 1988 which may not now reflect the current position and the Dorset study only related to three therapists. Nevertheless, in the absence of other data, these studies do provide a limited source of comparison and guidance for practitioners and managers.

\section{LITERATURE FROM OTHER COUNTRIES}

In assessing the relevance of literature from other countries to UK practice, there are several factors to consider. Classifications of mental illness, service provision, organisation of, and payment for, occupational therapy may differ. For instance, in the USA the salary of occupational therapists in mental health is usually less than their colleagues in physical disabilities and similarly reimbursement for occupational therapy in mental health is more restricted than it is for physical disabilities.

\section{American Journal of Occupational Therapy}

Much of current theory and practice in the UK has been influenced by literature from the USA, but this is less evident in mental health due to the scarcity of such literature. Like the British Journal of Occupational Therapy, its American counterpart has some clinically based articles but they are also characterised by breadth and infrequency of topic. It may be that more clinical articles are published Occupational Therapy in Mental Health, the quarterly journal in USA referred to in the introduction. The

dominant feature in the American Journal of Occupational Therapy has been concern 
about the diminishing number of therapists practising in mental health; the consequent impact on the profession; possible reasons for the problem and suggested remedies. In a study to measure the problem, Trickey and Kennedy (1995) reported that only $2 \%$ of occupational therapists in South Carolina worked in mental health. To establish their employment pattern, the administrators of 52 mental health facilities were surveyed. Of the 34 who responded, only $17 \%$ employed occupational therapists on a full-time basis, while $39 \%$ employed them on a part-time or contractual basis, $33 \%$ employed full-time and $11 \%$ employed part-time certified occupational therapy assistants.

In a frequently cited paper, Barris and Kielhofner (1986) invited educators across the USA to identify the major problems for mental health occupational therapy. Lack of a clear role definition was most frequently cited, with lack of a unifying theory and lack of research validating the profession also mentioned. Bonder (1987, p 495) noted that for the previous decade there had been anxiety that 'occupational therapy in mental health would disappear entirely as a result of unclear role delineations, increased competition form other professionals for decreased funding, and changes in the health care system.' She recognised the efforts of the American Occupational Therapy Association (AOTA) to cope with the problem but suggested that it had been reactive, rather than proactive. She proposed that good research was necessary, especially in areas of government priority. However, she also asked if this was a crisis or an opportunity for the profession.

The implication that the shortage of mental health practitioners might be related to their lack of competence was examined in a pilot study of 95 occupational therapists by Cottrell (1990). She found, to her surprise, that a high percentage judged their 
performance to be good or excellent. Also seeking reasons for the problem, Kleinman (1992) cited the profession's reliance on the medical model and that occupational therapists remained hospital based, when mental health services moved to the community. She proposed the adoption of a social model and the identification of the special features occupational therapy brings to mental health practice. These she suggested were emphasis on functional outcomes, activity analysis and a developmental perspective. She observed that 'although the number of occupational therapists working in mental health has dwindled, the number of people who need our services has not.' (p557)

Sladyk(1994, p134) questioned if some occupational therapists in physical disability practice were 'hastening the extinction of mental health practice' by adopting a narrow perspective and encouraging students and therapists to see physical disability as the preferred area of practice. Paul (1996, p65) recognised the stigma of mental illness and role blurring as major factors contributing to mental health being considered 'an endangered occupational therapy specialty'. His solutions were more efficacy studies; good fieldwork placements for students; a mandatory fieldwork placement in mental health; the AOTA making mental health a priority and the personal commitment of individual therapists.

\section{Student perspective}

Several authors have investigated the problem from a student perspective. Ezersky and her colleagues (1989) surveyed 411 graduates from nine schools in the New York area and their findings confirmed that fewer therapists worked in mental health. The 
principal reasons for selection of specialty were fieldwork experience, feeling effective in the area and perceptions of employment availability. Also examining specialty choice, Whittman and her colleagues (1989) retrospectively surveyed 212 occupational therapists before admission to University, at several points during their course and at job selection. Before the course $13 \%$ preferred mental health and this was only reduced to $12 \%$ at the time of job selection. The most negative aspect of education was the level 1, pre-clinical fieldwork placement.

Swinehart and Feinberg (1990) explored the relationship between admission criteria and practice preference in applicants to Indiana University and found that there was no bias against those favouring mental health. In view of this, and the findings of Whittman and her colleagues (1989), the authors suggested that in order to increase the number of occupational therapist in this area, priority could be given to those applicants expressing an interest in mental health.

Recognising the importance of fieldwork (Ezersky et al, 1989, Whittman et al, 1989, Paul,1996), two studies have explored this subject in more depth. Atwater and Davis (1990) surveyed 152 practitioners about their 12-week level 11 mental health placement. Of the 116 therapists who responded, only $8.6 \%$ worked exclusively in mental health, confirming the extent of the problem. More than half of the respondents $(55.2 \%)$ indicated that the placement had influenced their career choice and of these, $53.1 \%$ reported a positive influence. Therapists not working in mental health valued the mental health placement in their subsequent interactions with clients and their families citing dealing with anger, grief and depression. Supporting the opinion of Paul (1996) 84.5\% agreed that mental health fieldwork should be 
mandatory. However, as the number of occupational therapists in mental health reduced, Kautzmann (1995) noted that here was increased difficulty in finding placements. She questioned the practice of using alternative placements in areas such as pain management and hospices where aspects of psychosocial practice may be observed. In her opinion these may help to alleviate the short-term problem but, in the longer term, may serve to exacerbate the situation.

\section{Australian Occupational Therapy Journal}

As in other countries, publications in the Australian Occupational Therapy Journal about mental health are sparse. This is, to some extent, compensated for by the number that are found in the UK literature reinforcing the trend identified by Mountain (1997) of occupational therapists from other countries publishing in BJOT. In an early paper, Bartlow and Hartwig (1989) examined the status of practice, methods of assessment and frames of reference employed in mental health in Australia. Questionnaires were sent to 136 clinical occupational therapists, achieving a $65 \%$ response rate. In their opinion there was no clear consensus about scope of practice, assessments used or pattern of service delivery based on theoretical principles. They remarked on the 'limitations that the profession imposes on itself by its educational and clinical methods of operation' (p189).

In a personal retrospective, Weir (1991) outlined the changes in mental health over the past 30 years and highlighted her involvement in the establishment of a community based living skills centre in New South Wales in 1977. Although committed to a multidisciplinary approach, she was convinced of the essential role of occupational therapy, but expressed her concern that most practitioners tended to remain in the 
hospital setting rather than move into the community. Referring to the situation in the USA, she warned therapists that they must keep up to date with policy changes or they might be excluded from future mental health services.

Miller and Robertson (1991) advocated a role for the profession in crisis intervention and prevention. They considered that occupational therapists already had many of the relevant skills, in particular, creative problem solving. However, two aspects of the role provided new challenges; the level of responsibility for client care and the early and continuing contact with the client. They acknowledged a generic aspect to the occupational therapist's role but emphasised that a balance of different professions was valuable, as each contributed a unique approach. For Yau (1995), the unique role in community mental health focused on occupation. He identified four stages: assessment of occupational history, identification of deficits in occupational performance areas, acquisition of skills and encouraging clients to maintain their occupational performance. He considered that the profession could consolidate its position through valuing its special role and by collaborating with others.

\section{Canadian Journal of Occupational Therapy}

The role of occupational therapy in mental health was expounded by the Canadian Association of Occupational Therapists (1989) as a Position Paper in the Canadian Journal of Occupational Therapy. It provided a statement on the definitions of mental health; the client centred approach adopted by the Canadian Association; the theoretic perspective and occupational therapy process; manpower needs and future trends. Although Britnell (1989) acknowledged that the shortage of therapists was a fundamental problem in Canada, she adopted a more optimistic perspective and 
proposed that occupational therapy in mental health could be a growth industry. She cited emphasis on consumer participation as a key issue in Canada. A telephone survey of hospitals indicated growth of the profession in mental hospitals and an even greater potential for development in psychiatric units in general hospitals.

Examining the participation of consumers of mental health services in their treatment, Woodside (1991) noted that occupational therapists had skills to encourage them to be confident partners. The two features of occupational therapy that enabled this were client-centred practice and activity-based practice. The concept of consumer participation was extended by Clark et al (1993), who, in reviewing the literature, made a powerful case for involving clients in evaluating occupational therapy programmes. As client-centred practice is fundamental to the profession in Canada, client involvement in evaluating intervention is logical. They advised that the views of clients are 'essential to the continued development of occupational therapy.' (p197)

As in the Australian literature, there is reference to innovative methods of providing services for those with mental health problems. Krupa and Clark (1995) outlined the case management approach and its relationship to occupational therapy. In their opinion the similarities between them relate to adopting an holistic perspective, promoting independence and emphasising function rather than illness. However, some aspects of case management were less familiar to occupational therapists, namely crisis management, health education, resource development, family intervention, lobbying and advocacy. They concluded that occupational therapists were well placed to be case managers and that the role offered professional identity. 


\section{Discussion}

In conducting this review it has not been possible to include every article on occupational therapy in mental health, however, those cited make reference to others and thus the major themes have been identified. Of special interest is similarity of themes in each country.

On the positive side, the diversity and range of occupational therapy was well represented, with a continuing emphasis on novelty and innovation. There was a willingness to explore and extend the boundaries of occupational therapy, describing the development of new techniques and new roles for the profession. Although this is commendable, it could be inferred that occupational therapists prefer to pursue new areas of practice at the expense of validating current practice. This view was supported in the review of BJOT from 1989-96 which 'revealed a substantial proportion of papers that might be considered peripheral to the core activities of occupational therapists.' (Mountain, 1997, p433)

The shortage of articles on mental health was noticeable. Among those articles which have been published, the lack of research; lack of a clear definition of the profession; lack of information on the scope of practice and lack of articles featuring occupation were particularly lamented. Further, in the current climate of evidence based practice, the situation must be remedied if the profession is to progress.

In the British Journal of Occupational Therapy, four clinical topics predominated; dementia, work rehabilitation, community mental health and forensic psychiatry. It was encouraging to see that these subjects had been explored in some depth and that 
the body of knowledge about them has been expanded, although few of these articles emanated from previous ones. However, it is interesting to question if they best represent the practice of occupational therapy in the UK at present. If they do, why have other areas been neglected? If they do not, then why have therapists neglected to report their work in these other areas?

In the American Journal of Occupational Therapy, the decline in the number occupational therapists working in mental health was the foremost characteristic. Of particular interest was the way in which this issue has been tackled, becoming the focus of numerous articles which have augmented each other. An associated topic has been the perception of the situation from the student perspective and, in particular, the effect of fieldwork placements. As similar shortages have not been reported in the UK literature, it is tempting to think the problem does not exist here. However, the absence of evidence points more to the absence of research rather than the absence of the problem.

The possibility of Australian occupational therapists following the example of their colleagues in the USA and relinquishing mental health practice was recorded by Weir (1991). She advised practitioners to keep abreast of policy changes if they wanted to be included in future mental health services. Several Australian authors publishing in Australia and in the UK, have been at the forefront of exploring new directions for occupational therapy. (Moss, 1990, Miller and Robertson, 1991, Lloyd, 1995, Yau, 1995). However, this again raises the question of whether the focus of the profession should be diversification or consolidation. 
The most optimistic viewpoints on mental health appeared in the Canadian Journal of Occupational Therapy. The explicit and concise position paper, the focus on consumer participation and accent on client-centred practice provide useful exemplars demonstrating a distinct and concerted focus and strategy.

In relating the experiences of other countries to the UK, there is much to contemplate. Unlike the USA (Kleinman, 1992), occupational therapy in mental health in the UK has moved from hospital to community. Although this has caused many challenges for the profession, the chronic shortage of occupational therapists found in the USA has not been reported. However, the persistence of occupational therapists in USA in pursuing themes in research would be valuable example to follow. Also related to publishing, UK occupational therapists might consider the example of their colleagues in Australia and strive to publish in other countries. The creation in the UK of a collected vision of occupational therapy, as articulated by the Canadians, would have much to commend it.

\section{Conclusion}

This review has identified the major themes in the literature and posed many questions for therapists in practice, education and research. It formed the foundation for the work undertaken to prepare the position paper which suggests a way forward for individual therapists, occupational therapy services and the profession itself. 


\section{REFERENCES}

Atwater AW, Davies C G (1990) The value of psychosocial level 11 fieldwork. American Journal of Occupational Therapy, 44 (9), 792-5.

Baker R, Dowling Z, Wareing A, Dawson J, Assey J (1997) Snoezelen: its longterm and short-term effects on older people with dementia. British Journal of Occupational Therapy, 60(5), 213-18.

Barris R, Kielhofner G (1986) Beliefs, perspectives and activities of psychosocial occupational therapy educators. American Journal of Occupational Therapy, 40(8), 535-41.

Bartlow P, Hartwig C (1989) Status of practice in mental health : assessment of frames of reference. Australian Occupational Therapy Journal, 36 (4), 180-92.

Bertram M, Linnett P (1995) Empowerment through employment? an innovative work scheme for people with mental health problems. British Journal of Occupational Therapy, 58(1), 7-8.

Best D (1995) The developing role of occupational therapy in psychiatric intensive care units. British Journal of Occupational Therapy, 59(4), 161-4.

Blank A (1990) Coping with tranquilliser withdrawal use in South Wales. British Journal of Occupational Therapy, 53(6), 241-3.

Bonder B R (1987) Occupational therapy in mental health: crisis or opportunity? American Journal of Occupational Therapy, 41 (8), 495-9.

Bracegirdle H (1991) The female stereotype and occupational therapy for women with depression. British Journal of Occupational Therapy, 54(5), 193-4.

Brewer P, Gadsden V, Scrimshaw K (1994) The community group network in mental health: a model for social support and community integration. British Journal of Occupational Therapy, 57(12), 467-70.

Brintnell S (1989) Occupational therapy in mental health : a growth industry.

Canadian Journal of Occupational Therapy, 56(1), 7-9.

Brown G, Carmichael K (1992) Assertiveness training for clients with psychiatric illness: a pilot study. British Journal of Occupational Therapy, 55(4), 137-140.

Bryant W (1991) Creative group work with confused elderly people: a development of sensory integration therapy. British Journal of Occupational Therapy, 54(5), 18792.

Bryant W (1995) The social contact group: an example of long-tern group work in community mental health. British Journal of Occupational Therapy, 58(5), 214-18. 
Busuttil J (1994) Establishing psychosocial occupational therapy in an Arab country. British Journal of Occupational Therapy, 57(4), 124-6.

Canadian Association of Occupational Therapists (1989) Position paper on the role of occupational therapy in mental health. Canadian Journal of Occupational Therapy, 56 (2) $1-6$.

Carpenter P, Gardiner A, Palmer R (1990) The occupational therapy requirements of inpatients at a district psychiatric unit. British Journal of Occupational Therapy, 53(6), 225-28.

Clark C C, Scott E A, Krupa T (1993) Involving clients in programme evaluation and research: a new methodology for occupational therapy. Canadian Journal of Occupational Therapy, 60 (4), 192-9.

Cottrell R F (1990) Perceived competence among occupational therapists in mental health. American Journal of Occupational Therapy, 44 (2), 118 -24.

Crawford G, Johnston S, Morris S, Steeples S (1992) Are norms the key to manpower planning? British Journal of Occupational Therapy, 55(2), 49-52.

Creegan S (1995) An investigation of vocational programmes and services in North America. British Journal of Occupational Therapy, 58(1), 9-13.

Durham T (1997) Work-related activity for people with long tern schizophrenia: a review of the literature. British Journal of Occupational Therapy, 60(6), 248-52.

Evans E (1990) Who is the client? The community occupational therapy support to elderly dementia patients and their carers in West Dorset. British Journal of Occupational Therapy, 53(7), 280-84.

Evans E (1996) Information systems: can they determine how occupational therapists spend their time in the care of people with dementia and their carers? British Journal of Occupational Therapy, 59(7), 307-12.

Ezersky S, Havazelet L, Hiller-Scott A, Zetler CL (1989) Specialty choice in occupational therapy. American Journal of Occupational Therapy, 43 (4), 227-33.

Flood B (1993) Implications for occupational therapy services following the Reed report. British Journal of Occupational Therapy, 56(8), 293-4.

Garner R (1995) Prevocational training within a secure environment: a programme designed to enable forensic patients to prepare for mainstream opportunities. British Journal of Occupational Therapy, 58(1), 2-6.

Garner R, Butler G, Hutchings D (1996) A study of the relationship between patterns of planned activity and incidents of deliberate self harm within a regional secure unit. British Journal of Occupational Therapy, 59(4), 156-60. 
Gilbert J, Strong J (1994) Dysfunctional attitudes in patients with depression: a study of patients admitted to a private psychiatric hospital. British Journal of Occupational Therapy, 57(1), 15-19.

Gilbert J, Strong J (1997) Australian occupational therapy students: attitudes towards and knowledge about psychiatry. British Journal of Occupational Therapy, 60(1), 12 16.

Green S (1995), Elderly mentally ill people and quality of life; who wants activities? British Journal of Occupational Therapy, 58(9), 377-82.

Harries P, Caan W (1994) What do psychiatric inpatients and ward staff think about occupational therapy. British Journal of Occupational Therapy, 57(6), 219-223.

Jeffrey LH (1993) Aspecs of selecting outcome measures to demonstrate the effectiveness of comprehensive rehabilitation. British Journal of Occupational Therapy, 5611, 394-440

Joice A, Coia D (1989) A discussion on the skills of the occupational therapist working within a multidisciplinary team. British Journal of Occupational Therapy, 52(12), 466-48.

Kaur D, Seager M, Orrell M (1996) Occupation or therapy? The attitudes of mental health professionals. British Journal of Occupational Therapy, 59(7), 319-22.

Kautzmann L N (1995) The issue is. Alternatives to psychosocial fieldwork: part of the solution or part of the problem? American Journal of Occupational Therapy, 49 (3), 266-8.

Kleinman B L (1992) The challenge of providing occupational therapy in mental health. American Journal of Occupational Therapy, 46 (6), 555-7.

Krupa T, Clark C C (1995) Occupational therapists as case managers; responding to current approaches to community mental health service delivery, Canadian Journal of Occupational Therapy, 62 (1), 16-22.

Lake B, Burgess J (1989) Mental health and mental illness: educating sixth-formers, British Journal of Occupational Therapy, 52(8), 301-4.

Lim PY, Agnew P (1994) Occupational therapy with eating disorders: a study of treatment approaches. British Journal of Occupational Therapy, 57(8), 309-314.

Lloyd C (1995) Trends in forensic psychiatry. British Journal of Occupational Therapy, 58(5), 209-13.

Lloyd C and Maas F (1997) Occupational therapy group work in psychiatric settings. British Journal of Occupational Therapy, 60(5), 194-98. 
Lyons M (1995) Learning in context: perceived benefits of fieldwork education in community mental health settings, British Journal of Occupational Therapy, 58(6), 245-49.

McDougall S (1992), The effect of nutritional education on the shopping and eating habits of a small group of chronic schizophrenic patients living in the community. British Journal of Occupational Therapy, 55(2), 62-68.

Miller V, Robertson S (1991) A role for occupational therapy in crisis intervention and prevention. Australian Occupational Therapy Journal, 38(3), 143-6.

Moss B A (1990) Living skills centres: a part of Australia's community mental health service. British Journal of Occupational Therapy, 53(3), 112-13.

Mountain G (1997) A review of the literature in the British Journal of Occupational Therapy 1989- 1996. British Journal of Occupational Therapy, 60(10), 432-435.

O'Neill H (1995) The assessment and treatment of problematic anger Parts 1 and 2. British Journal of Occupational Therapy, 58(10)427-31, 58(11)469-72.

Orford J (1995) Community mental health : the development of the CCOPII, a client centred, occupational performance initial interview. British Journal of Occupational Therapy, 58(5), 190-96.

Oxley C (1992) Devising an assessment package for an employment rehabilitation service. British Journal of Occupational Therapy, 55(12), 448-52.

Oxley C (1995) Work and work programmes for clients with mental health problems. British Journal of Occupational Therapy, 58(11), 465-68.

Paul S (1996) Mental health: an endangered occupational therapy specialty. American Journal of Occupational Therapy, 50 (1), 65-8.

Pinkey L (1997) A comparison of the Snoezelen environment and a music relaxation group on the mood and behaviour of patients with senile dementia. British Journal of Occupational Therapy, 60(5), 209-12.

Robinson S (1992), Occupational therapy in a memory clinic. British Journal of Occupational Therapy, 55(10), 394-96.

Roberts G (1995) Trauma following major disasters: the role of the occupational therapist. British Journal of Occupational Therapy, 58(5), 204-8.

Sainty M (1993) Dementia: the marriage relationship and the concept of relief. British Journal of Occupational Therapy, 56(7), 238-42.

Sexton D (1992) Kirkton companions, the clients assess: evaluating a community mental health day facility. British Journal of Occupational Therapy, 55(11), 414-8. 
Sladyk K (1994) Are some occupational therapists in physical disability practice settings hastening the extinction of mental health practice? American Journal of Occupational Therapy, 48 (2), 174-5.

Swinehart S, Feinberg J (1990) The relationship between admission criteria and practice performance. American Journal of Occupational Therapy, 44 (5), 447-52.

Telford R, Ainscough K (1995) Non-directive play therapy and psycodynamic theory: never the twain shall meet? British Journal of Occupational Therapy, 58(5), 201-3.

Trickey BA, Kennedy D B (1995) Use of occupational therapists in mental health settings in South Carolina. American Journal of Occupational Therapy, 49 (5), 452-5.

Vostanis P (1990) The role of work in psychiatric rehabilitation; a review of the literature. British Journal of Occupational Therapy, 53(10), 24-28.

Weir W (1991) Emerging from behind closed doors. Australian Occupational Therapy Journal, 38(4), 185 -92.

Westland G (1988) Relaxing in primary health care. British Journal of Occupational Therapy, 51(3), 84-8.

Whittman P P, Swinehart S, Cahill R, St Michael G (1989) Variables affecting specialty choice in occupational therapy. American Journal of Occupational Therapy, 43 (9), 602-6.

Woodside H (1991) The participation of mental health consumers in health care issues. Canadian Journal of Occupational Therapy, 58 (1), 3-5.

Yau MKS (1995) Occupational therapy in community mental health: do we have a unique role in the interdisciplinary environment ? Australian Occupational Therapy Journal, 42 (3),129-32. 


\section{Acknowledgements}

The author would like to thank Dominique Le Marchand and the staff of the Library of the College of Occupational Therapists for their assistance with this review and the members of the Mental Health Project Working Group for their support. 